Original Article

Artigo Original

Karen Fontes Luchesi ${ }^{1}$

Bruna Magnani Campos ${ }^{1}$

Claudia Tiemi Mituuti ${ }^{1}$

Keywords

Neurodegenerative Diseases

Swallowing

Speech, Language and Hearing

Dysphagia

Prevention

Palavras-chave

Doenças Neurodegenerativas Deglutição Fonoaudiologia Disfagia Prevenção

Correspondence address:

Karen Fontes Luchesi

Departamento de Fonoaudiologia,

Centro de Ciências da Saúde - CCS,

Universidade Federal de Santa Catarina

- UFSC

Rua Delfino Conti, s/n, Campus

Universitário, Trindade, Florianópolis

(SC), Brasil, CEP: 88040-900.

E-mail: karenluchesi@yahoo.com.br

Received: August 16, 2017
Identification of swallowing disorders:

the perception of patients with

neurodegenerative diseases

\section{Identificação das alterações de deglutição: percepção de pacientes com doenças neurodegenerativas}

\begin{abstract}
Purpose: To verify the perception of patients with neurodegenerative diseases regarding swallowing changes and to know the perceptions of swallowing sensations that can promote the early identification of dysphagia Methods: It is a cross-sectional study with 44 patients with neurodegenerative diseases. All of them answered a questionnaire to know the sensation perceived during swallowing and its intensity. The Fatigue Severity Scale was applied to measure fatigue and the Swallowing Disturbance Questionnaire was applied to detect swallowing complaints. The Functional Oral Intake Scale was used to classify the swallowing functionality. Videofluoroscopic swallowing study (VFSS) was performed to verify the correspondence between the patient's perceptions and swallowing physiopathology. A descriptive and exploratory statistical analysis was performed. Results: There was correspondence between VFSS findings and the patient's perception in $76.5 \%$ of the cases. Sensations such as discomfort and fatigue were perceived during swallowing, especially with solids. Such feelings have predominantly been reported in the throat, from the half to the end of the meal. There was association between fatigue and odynophagia. Fatigue during swallowing was associated with worse functionality of oral intake. Conclusion: Most participants perceived the disorders in their swallowing. Sensations such as burning, discomfort, tiredness, pain, cramp, or irritation were perceived by participants and were associated with symptoms that may suggest risk of aspiration due to fatigue resulting from weakness, incoordination, and/or stiffness of muscles.
\end{abstract}

\section{RESUMO}

Objetivo: Verificar a percepção de indivíduos com doenças neurodegenerativas quanto às alterações de deglutição, e conhecer as sensações ao deglutir que podem favorecer a identificação precoce de disfagia. Método: Trata-se de um estudo transversal com 44 sujeitos com doenças neurodegenerativas. Todos responderam a um questionário para investigação da sensação percebida ao deglutir e mensuração da intensidade da sensação. Foram questionados quanto à presença de fadiga por meio da Fatigue Severity Scale. Para detecção de queixas de deglutição, foi utilizada a versão traduzida e adaptada para o português brasileiro do Swallowing Disturbance Questionaire. A Funcional Oral Intake Scale foi utilizada para classificar o nível de ingestão oral. Realizou-se videofluoroscopia da deglutição para verificar a correspondência entre a percepção dos participantes e a fisiopatologia da deglutição. Foi realizada análise estatística descritiva e exploratória. Resultados: Houve correspondência entre os achados da videofluoroscopia e a percepção dos sujeitos em $76,5 \%$ casos. Sensações como desconforto, cansaço e incômodo foram percebidas ao engolir, especialmente, na consistência sólida. Tais sensações foram referidas, predominantemente, na região da garganta, da metade para o final das refeições. Houve associação entre fadiga durante a alimentação e odinofagia. A fadiga durante a deglutição foi associada à pior funcionalidade oral. Conclusão: A maioria dos participantes percebeu as alterações presentes em sua deglutição. Sensações como ardor, desconforto, incômodo, cansaço, dor, câimbra ou irritação foram referidas pelos participantes e se mostraram associadas com sinais e sintomas que sugerem risco de aspiração laringotraqueal, especialmente, devido à fadiga muscular decorrente de fraqueza, incoordenação e/ou rigidez da musculatura.

Study conducted at Departamento de Fonoaudiologia, Universidade Federal de Santa Catarina - UFSC Florianópolis, (SC), Brasil.

${ }^{1}$ Departamento de Fonoaudiologia, Universidade Federal de Santa Catarina - UFSC - Florianópolis (SC), Brasil. Financial support: nothing to declare.

Conflict of interests: nothing to declare. 


\section{INTRODUCTION}

Dysphagia is a swallowing disorder that affects the ability to carry food or fluids from the mouth to the stomach ${ }^{(1)}$. It is a symptom of an underlying disease and usually manifests as coughing and/or choking during or after a meal ${ }^{(2)}$.

Diseases that affect tissues or pathways essential for the neural control of swallowing may cause neurogenic dysphagia ${ }^{(3)}$. When progressive, such diseases are usually called neurodegenerative diseases and are characterized by the loss of specific populations of neurons ${ }^{(4)}$.

Since changes in the nervous system can lead to dysphagia, it is important to know the physiopathology of each disease and to know the sensory and motor origin of the signs and symptoms of swallowing changes ${ }^{(3)}$. The knowledge of these aspects will help in the definition of the Speech-Language Therapist (SLT) course of treatment appropriate to favor the safety and quality of life of the patient ${ }^{(5)}$.

The identification of signs and symptoms by the individual during oral feeding may be a factor of attention for health professionals in the early identification of dysphagia and its evolution.

When it is identified early, dysphagia can be monitored and its complications, such as dehydration, malnutrition and pneumonia can often be prevented. When necessary, an alternative feeding pathway may be indicated at the optimum time for increased survival in certain cases. Even when the alternative feeding pathway is not chosen by the patient, the discomfort caused by gagging can be minimized by SLT management of swallowing, increasing well-being and promoting the individual's quality of life.

This article aimed to verify the perception of individuals with neurodegenerative diseases regarding swallowing changes and to know the swallowing sensations that may favor the early identification of dysphagia.

\section{METHODS}

This was a cross-sectional observational study. We included adult individuals with neurodegenerative diseases, attended at the neurology outpatient clinic and / or at a dysphagia outpatient clinic of a tertiary hospital in Santa Catarina, Brazil. Participating in the research were only those who had some type of communication (oral, alternative or gestural). Subjects who showed difficulty understanding during the application of collecting instruments or comorbidities that were known to alter swallowing functionality (such as head and neck cancer, neurosurgery, stroke or head trauma) were excluded.

An instrumental evaluation of swallowing was performed by videofluoroscopic swallowing study (VFSS). In the examination, three offers of consistencies ${ }^{(6)}$ were made: liquid in a cup (free swallowing), pudding (in the patient's usual spoon) and solid (on demand). The contrast was obtained as follows: $30 \%$ water to $70 \%$ barium sulphate (BaSO4), the pudding consistency being prepared according to the recommendation of the manufacturer of the food thickener used (Thick Easy ${ }^{\circledR}$ ). The solid consistency consisted of the offer of a cream cracker biscuit in BaSO4.
The VFSS was performed in the radiology department of a tertiary hospital by a physician, radiology technician and SLT who was also responsible for the offer of the food. The foods were offered to the patients in the following sequence: liquid, pudding and solid. The participants were placed in a sitting position (lateral and anteroposterior) in a special chair, adapting posture when needed. The examination was performed with a remote-controlled sero-apparatus and recorded on video for later analysis.

The results of the VFSS were qualitatively analyzed by the consensus of two SLT specialized in dysphagia to identify the presence or absence of airway permeation (laryngeal penetration or laryngotracheal aspiration), pharyngeal residues and/or change in the oral phase of swallowing.

A questionnaire was applied to collect identification data, neurological diagnosis, disease time, presence of SLT follow-up and respiratory support. Also noted were the presence or absence of unpleasant sensations when swallowing (burning, discomfort, annoyance, tiredness/fatigue, cramps, irritation or pain/odynophagia), duration of sensation (acute or continuous), moment of sensation (beginning, middle or end of the meal) and site (mouth, throat, neck or chest). Participants were instructed to choose how many alternatives were needed to best represent their perception. They were instructed to select a number from zero to ten to measure the intensity of perceived sensation when swallowing, with zero being none and ten being very intense.

Since many patients may present fatigue as one of the subjective perceptions of the pathophysiological process of neurodegenerative diseases, the Fatigue Severity Scale (FSS) was applied ${ }^{(7-9)}$. The scale comprises of nine statements about how fatigue interferes with motivation, physical performance, performance of duties, responsibilities and work; whether exercises causes fatigue; whether fatigue is a frequent cause of the problem and whether it is one of the most disabling symptoms experienced. The individual was instructed to remember the last two weeks and respond to each statement with a score of one to seven (one indicates that the participant disagrees completely and seven indicates that the participant fully agrees with the statement made). Each subject could have a score of 9 to 63 , with greater or equal to 28 being indicative of fatigue ${ }^{(10)}$.

In addition to the nine questions on overall fatigue in the FSS, two statements were added about fatigue during feeding: "I feel fatigued during meals" and "Fatigue interferes with my eating". Participants were instructed to respond whether they agreed or disagreed with these assertions, which were analyzed in isolation and were not included in the FSS score.

All responded to the Swallowing Disturbance Questionnaire (SDQ), translated and adapted to Brazilian Portuguese ${ }^{(11)}$, for the detection of swallowing complaints. The SDQ is composed of 15 closed questions about the difficulty of swallowing perceived by the subjects at different times and in different ways. It contains four alternatives for graduation of the answer, with zero meaning never, one rarely, two frequently and three very often. For this study, only swallowing complaints with responses greater than one were considered. 
Participants were also classified according to the Functional Oral Intake Scale (FOIS) ${ }^{(12)}$, which classifies the oral intake from one to seven, one of which is equivalent to no oral intake and seven to the oral route without restrictions.

The correlation between swallowing complaints and VFSS findings was verified by categorizing each participant in: 1) Whether there is a correspondence between the complaints and the findings in the VFSS: in cases in which changes in oral and/or pharyngeal swallowing phases identified in the exam were self-referenced in the SDQ; 2) Whether there is partial correspondence between the complaints and the findings in the VFSS: in cases in which not all the changes observed in the exam have been identically identified in the SDQ; 3) Whether there is no correspondence between swallowing complaints and VFSS findings: in the cases of participants who did not answer affirmatively to any question of the SDQ that was equivalent to the changes observed in the VFSS.

All were approached before or after the consultations in the neurology or dysphagia outpatient clinic of the before mentioned hospital and the questionnaires were answered by the participant himself.

\section{Data analysis}

A descriptive analysis of the data was performed by obtaining the measures of central tendency and dispersion of the numerical variables, as well as obtaining the absolute and relative frequencies of the categorical variables. For the exploratory analysis, the Statistical Package for the Social Sciences (SPSS) software for Windows was used and considered as variables of interest: swallowing complaints; the amount of sensations perceived during swallowing; the intensity, the site, the duration and the moment of the referred sensation; odynophagia; being in SLT follow-up; classification in FOIS; the age; disease duration; score on the fatigue scale; the complaint of fatigue during eating.

Fisher's exact test, chi-square, Spearman's correlation, Mann-Whitney $U$ test and Kruskal-Wallis test were used and only p-values less than 0.05 were considered significant.

This study respects the Resolution of Helsinki Resolution and resolution number 466/2012. All participants gave written informed consent. The study was approved by the Research Ethics Committee of the Universidade Federal de Santa Catarina, under protocol no. 1.452.487.

\section{RESULTS}

The study population consisted of 44 subjects with neurodegenerative diseases, according to the descriptive analysis contained in Table 1 and Figure 1. Amyotrophic lateral sclerosis was the most frequent disease.

Only 17 (38.6\%) participants underwent VFSS. All those who underwent the examination had pharyngeal changes and

Table 1. Descriptive analysis of aspects related to swallowing and diagnosis of patients with neurodegenerative diseases undergoing outpatient follow-up between 2015 and $2016(n=44)$

\begin{tabular}{|c|c|c|c|}
\hline Variables & Min-Max & Mean \pm SD & Median \\
\hline Age (years) & $19-81$ & $49.4 \pm 14.8$ & 51 \\
\hline Disease duration (months) & $6-528$ & $58.7 \pm 81.8$ & 36 \\
\hline Number of sensations $(n)$ & $0-6$ & $0.95-1.44$ & 0 \\
\hline Intensity of sensations (0-none / 10-maximum) & $0-10$ & $3.36 \pm 3.79$ & 0 \\
\hline FOIS & $5-7$ & $6.23 \pm 0.83$ & 6 \\
\hline Fatigue scale score & $0-63$ & $17.9 \pm 23.3$ & 0 \\
\hline Complaint of fatigue during eating & & $18 \%(8)$ & \\
\hline Presence of overall fatigue & & $29 \%(13)$ & \\
\hline
\end{tabular}

Caption: FOIS - Functional Oral Intake Scale; Min-Max - minimum and maximum value; SD - standard deviation

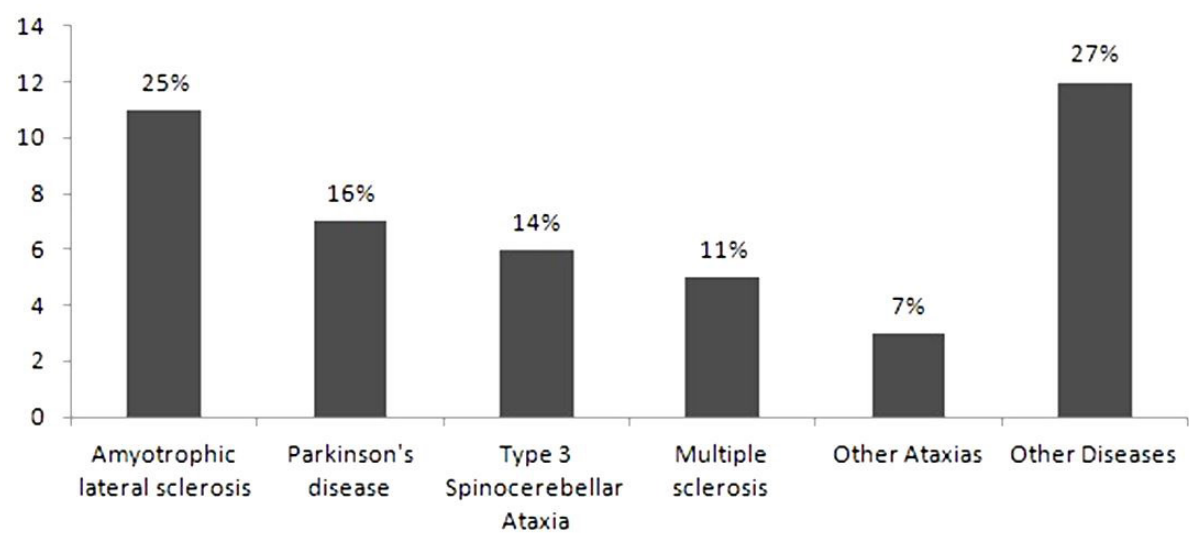

Figure 1. Frequency of neurodegenerative diseases in patients undergoing outpatient care between 2015 and $2016(n=44)$ 
$14(77.7 \%)$ presented changes in the oral phase of swallowing. Seventeen (100\%) presented pharyngeal residues, five $(29.4 \%)$ had laryngeal penetration and one $(5.8 \%)$ had laryngotracheal aspiration.

Nineteen (43\%) participants reported one or more unpleasant sensations during swallowing (Figure 2). Fifty-five percent (11 subjects) reported that such sensation was acutely felt during swallowing, the others perceived it continuously.

The solid consistency was cited by $85 \%$ (17 participants) with swallowing complaint, as the most unpleasant triggering sensation when swallowing. Sixty-five percent (13 participants) perceived burning, discomfort, annoyance, tiredness, odynophagia, cramp or irritation in the throat when swallowing daily. These sensations were also perceived in the mouth by $20 \%$ (4 subjects), in the chest by $10 \%$ (two subjects) and in the neck by $5 \%$ (one subject). Sixty percent ( 12 participants) noted them from half the meals, $30 \%$ (six) at the end and $10 \%$ (two) at the beginning of the meal.

There was an association between reports of fatigue during eating and odynophagia (pain when swallowing). Fatigue during eating was associated with greater number of sensations when swallowing, higher intensity of such sensations and worse classification in FOIS (Table 2).

Participants' ages and time of illness were not associated with the amount or intensity of swallowing sensations. There was also no association between age or time of illness with the reporting of overall fatigue, fatigue during eating or even with FOIS classification. There was a correlation between age and difficulty in breathing during meals, with the greater the age, the greater the difficulty ( $p$-value $0.040, r=0.50$ ).

Overall, 56\% (25 individuals) were under SLT follow-up. The older participants, with more swallowing sensations, greater intensity of sensation and worse FOIS, significantly made up the subjects in SLT follow-up (Table 2).

There was an empirical correlation between swallowing complaints and VFSS findings in 76.5\% (13 of the 17 who underwent the examination) of the participants. In only one case was there no correspondence between the complaints and the findings of the examination (Chart 1).

Table 2. Exploratory analysis of aspects related to swallowing and the diagnosis of patients with neurodegenerative diseases in outpatient follow-up between 2015 and $2016(n=44)$

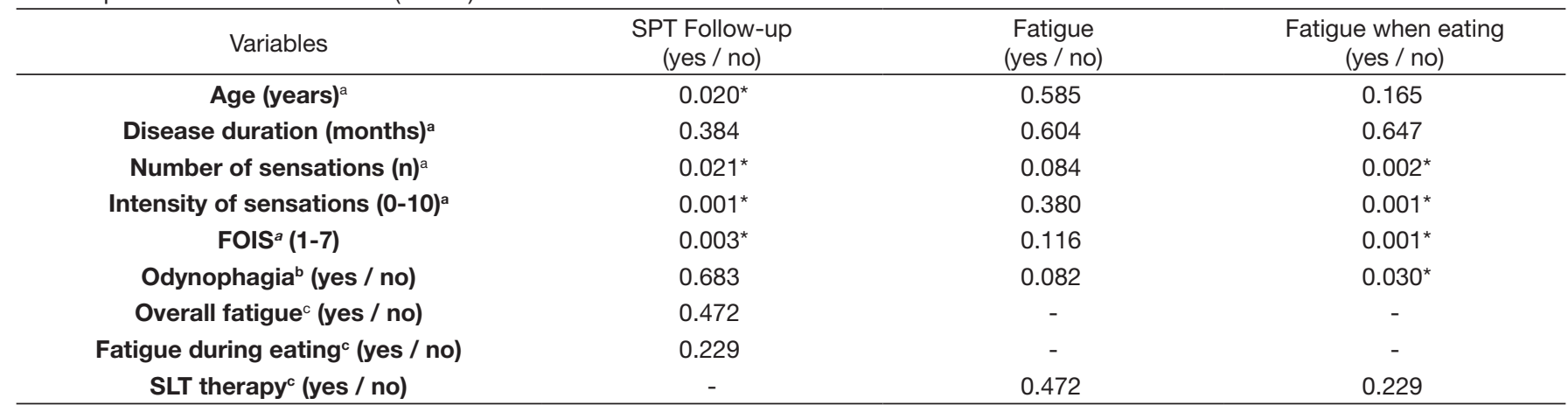

aMann-Whitney $U$ test; ${ }^{\text {b}}$ Fisher's exact test; ${ }^{\circ}$ Chi-squared; ${ }^{*} p$-value $<0.05$

Caption: FOIS - Functional Oral Intake Scale

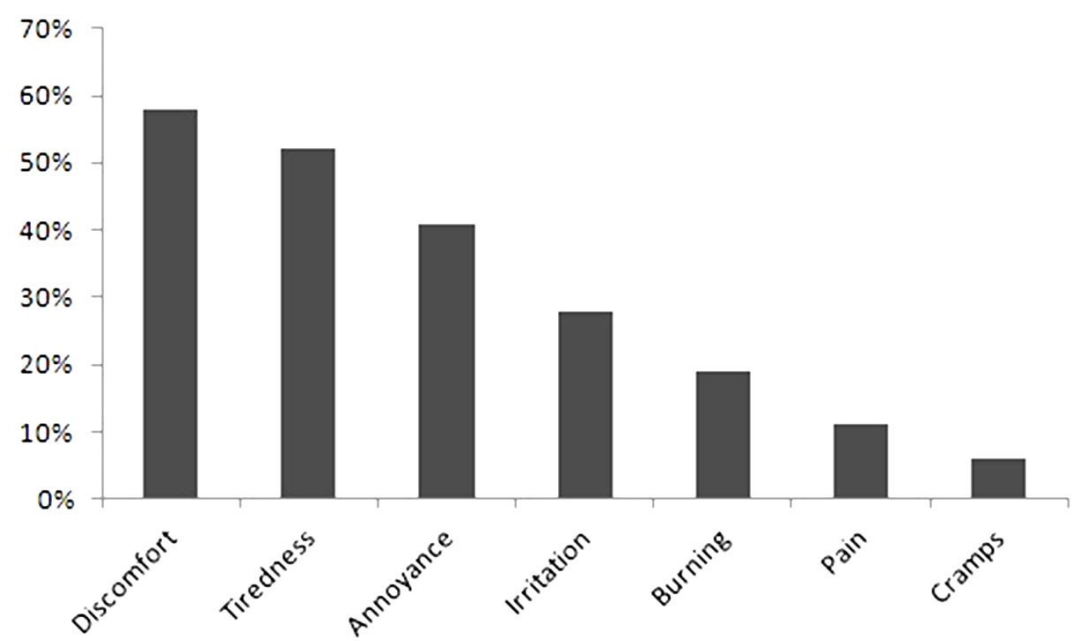

Figure 2. Frequency of perceived sensations during swallowing by patients with neurodegenerative diseases in outpatient follow-up between 2015 and $2016(n=19)$ 


\begin{tabular}{|c|c|c|c|c|c|c|c|c|c|}
\hline & \multicolumn{2}{|c|}{ 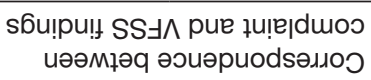 } & $\begin{array}{l}\text { 卺 } \\
\widetilde{\sigma}\end{array}$ & 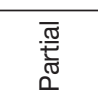 & $\stackrel{\infty}{\rightleftharpoons}$ & $\stackrel{\infty}{\rightleftharpoons}$ & $\stackrel{\infty}{\varnothing}$ & $\begin{array}{l}\text { 卺 } \\
\widetilde{\sigma}\end{array}$ & 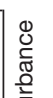 \\
\hline & \multicolumn{2}{|r|}{ Oas } & 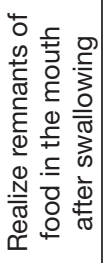 & 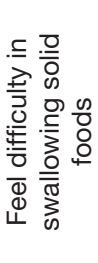 & 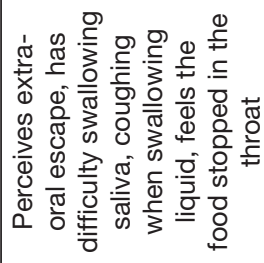 & 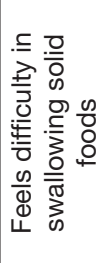 & 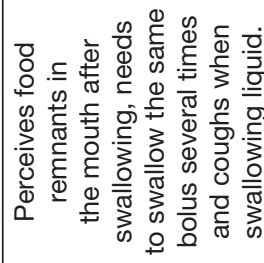 & 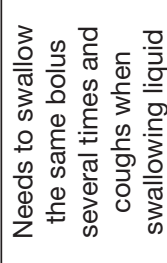 & 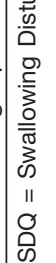 \\
\hline & \multicolumn{2}{|r|}{$\mathrm{SIOH}$} & $\wedge$ & 0 & 0 & ᄂ & $\infty$ & 0 & \\
\hline \multirow{5}{*}{ 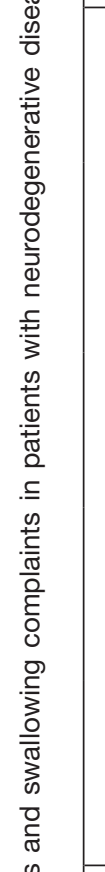 } & \multirow{5}{*}{ 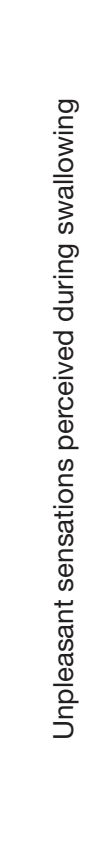 } & 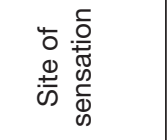 & ' & $\begin{array}{l}\frac{u}{0} \\
\frac{d}{2}\end{array}$ & 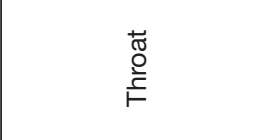 & 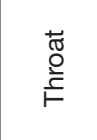 & 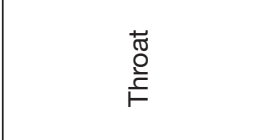 & ' & E⿸\zh14𠄌⿺𠃊乛龰 \\
\hline & & $\begin{array}{l}\vec{े} \\
\frac{0}{0} \\
\frac{0}{00} \\
\frac{0}{00} \\
0 \\
0\end{array}$ & ' & $\frac{\overline{0}}{\overline{0}}$ & $\begin{array}{l}\frac{\overline{0}}{\bar{y}} \\
\frac{\mathrm{O}}{3}\end{array}$ & $\begin{array}{l}\text { 음 } \\
\text { œ }\end{array}$ & $\frac{\overline{\underline{D}}}{\overline{\bar{y}}}$ & ' & 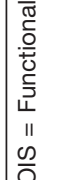 \\
\hline & & 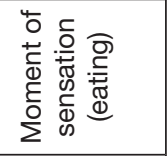 & ' & 훈 & $\begin{array}{l}\frac{4}{\pi} \\
\frac{\pi}{1}\end{array}$ & $\frac{\frac{4}{\pi}}{\frac{\pi}{I}}$ & 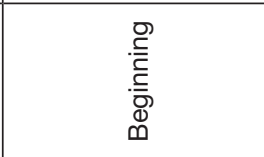 & ' & 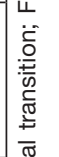 \\
\hline & & 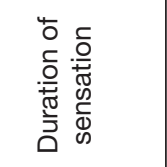 & 1 & 营 & 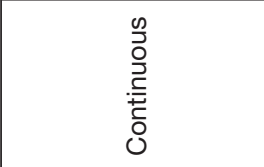 & 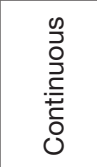 & 营 & ' & 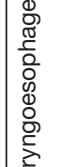 \\
\hline & & 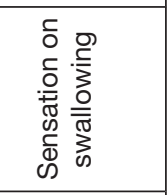 & $\begin{array}{l}0 \\
\stackrel{0}{0} \\
z\end{array}$ & 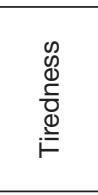 & 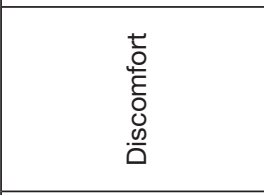 & 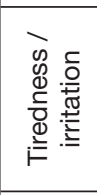 & 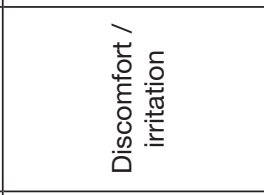 & $\begin{array}{l}0 \\
\frac{0}{0} \\
z\end{array}$ & \\
\hline \multirow{8}{*}{ 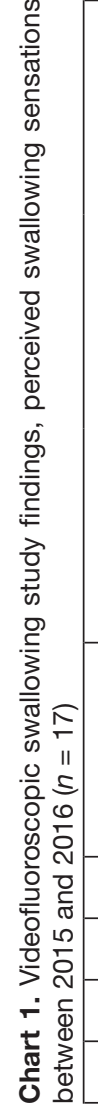 } & \multirow{3}{*}{ 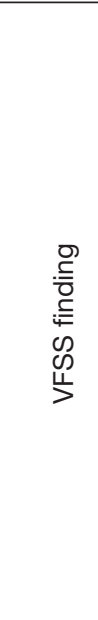 } & $\begin{array}{l}\frac{\overline{0}}{\overline{0}} \\
\text { œ }\end{array}$ & 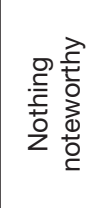 & 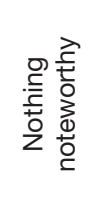 & 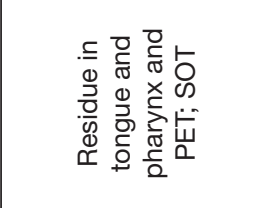 & 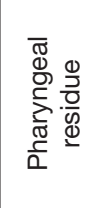 & 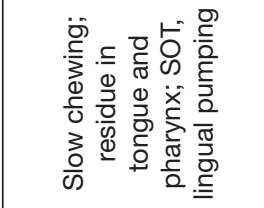 & 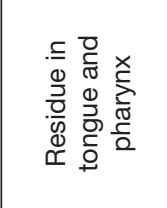 & $\begin{array}{l}\bar{\partial} \\
\bar{d} \\
z_{0}^{2} \\
\frac{0}{\omega}\end{array}$ \\
\hline & & $\begin{array}{l}\frac{0}{5} \\
\frac{\overline{0}}{0} \\
\frac{0}{0}\end{array}$ & 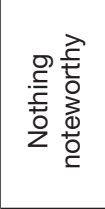 & 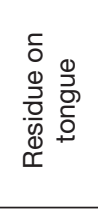 & 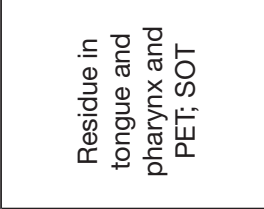 & 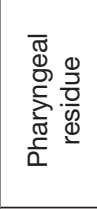 & 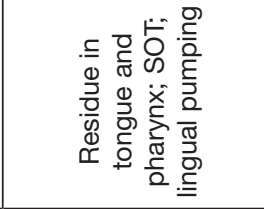 & 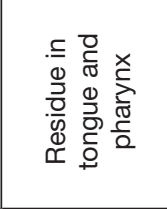 & 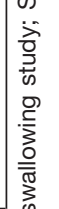 \\
\hline & & $\frac{\bar{O}}{\bar{y}}$ & 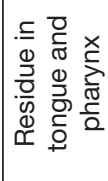 & 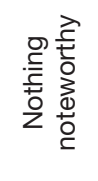 & 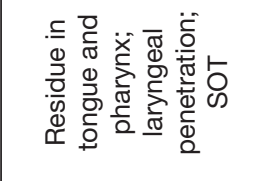 & 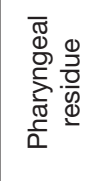 & 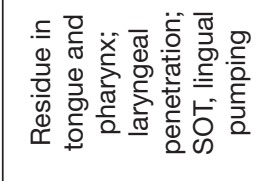 & 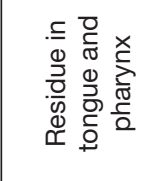 & 这 \\
\hline & \multicolumn{2}{|c|}{ 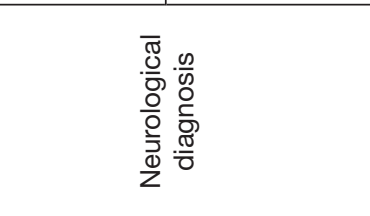 } & 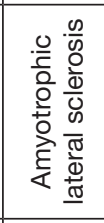 & 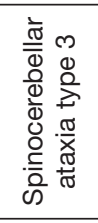 & 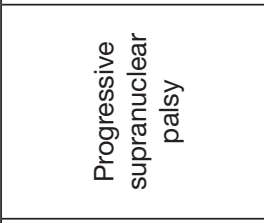 & 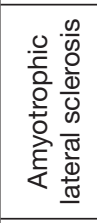 & 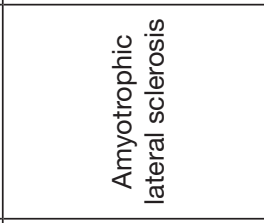 & 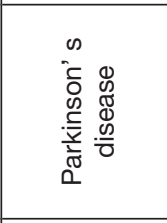 & \\
\hline & \multicolumn{2}{|c|}{ 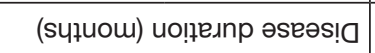 } & $\stackrel{\sim}{\sim}$ & 8 & $\stackrel{\infty}{\sim}$ & $\stackrel{\sim}{\leftarrow}$ & $\stackrel{\infty}{+}$ & $\stackrel{\infty}{+}$ & \\
\hline & \multicolumn{2}{|r|}{$($ sıeə $)$ ) әб $\forall$} & $\bar{n}$ & $\bar{\forall}$ & $\hat{\theta}$ & 오 & $\mathscr{f}$ & $\hat{\theta}$ & \\
\hline & \multicolumn{2}{|r|}{ xəS } & $\Sigma$ & \llcorner & $\Sigma$ & $\Sigma$ & $\Sigma$ & $\leftarrow$ & \\
\hline & \multicolumn{2}{|r|}{ łued!̣!nued } & $\tau$ & $N$ & $m$ & $\checkmark$ & م & 0 & \\
\hline
\end{tabular}




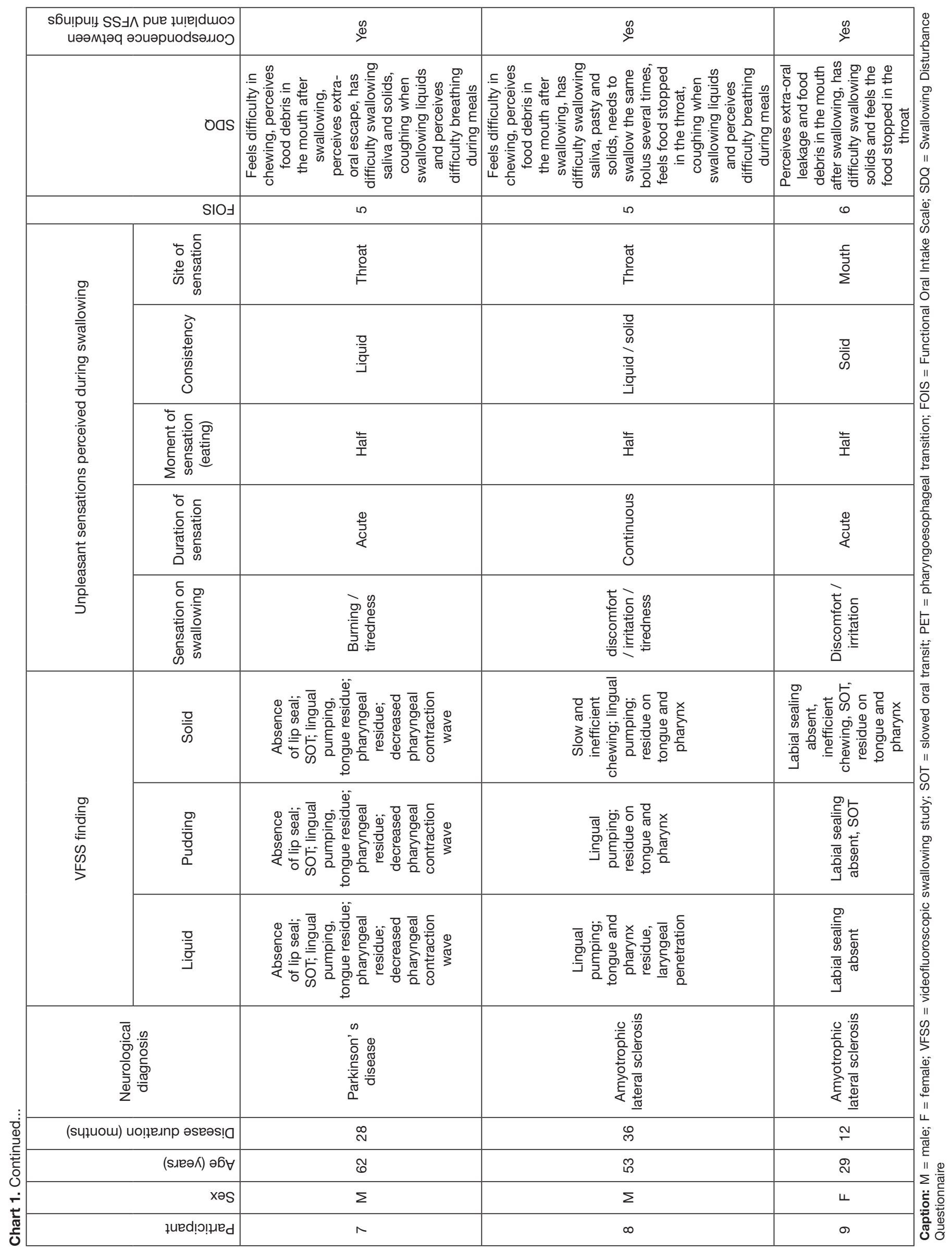




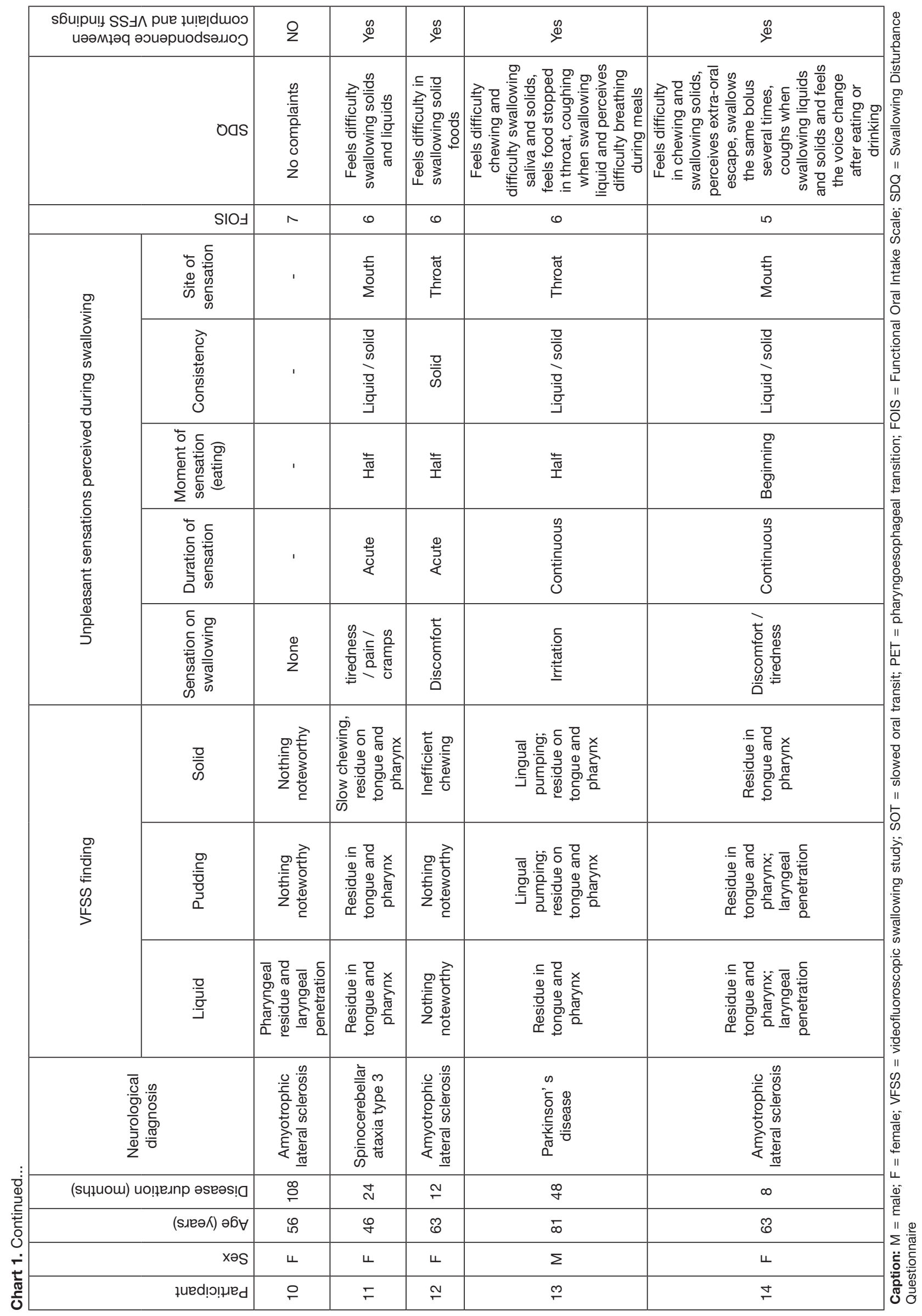




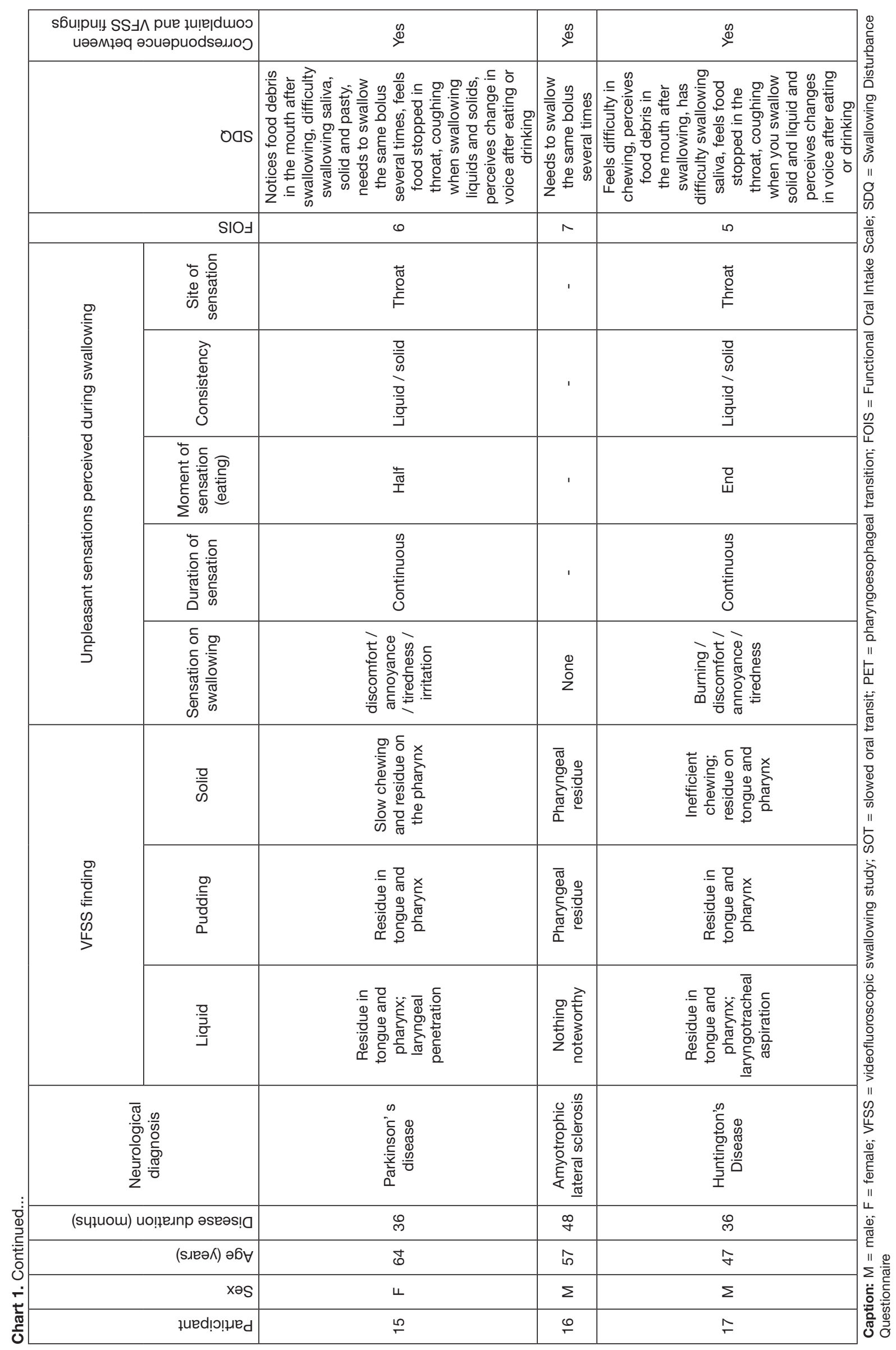




\section{DISCUSSION}

In the present study, it was observed that approximately $50 \%$ of the participants had diseases that could compromise oropharyngeal and laryngeal sensitivity. However, there were several sensations and difficulties perceived in swallowing when comparing the complaints and VFSS findings.

According to the literature, sensations such as odynophagia can be explained by spasticity, atrophy, stiffness and changes in muscle tone. The perception of this sensation on swallowing may consequently alter mobility, reduce motor coordination, and affect muscle function for bolus feeding and opening of pharyngoesophageal transition ${ }^{(13)}$.

Some degenerative diseases lead to muscle denervation, producing weakness and hypotonia. Being weaker, muscles require more work from the individual, leading to greater intensity for performing the function and progressively inducing fatigue and a greater sense of effort. Such sensations can also be described by the patient as pain ${ }^{(14)}$, burning, cramp, irritation, discomfort, annoyance and tiredness.

If there is more fatigue or tiredness for reasons such as weakness, stiffness or incoordination, the musculature responsible for the propulsion of the bolus and the protection of the airways may have its functionality impaired. As observed in the present study, patients who reported fatigue during eating presented a greater number of complaints during swallowing and also worse functionality for oral ingestion.

The sensations were more acutely perceived by the participants and located in the throat, where the ejection and the conduction of the food bolus to the pharynx were recognized.

As observed in the VFSS, fatigue, stiffness or incoordination in the oral phase of swallowing can cause changes such as sluggishness and less efficiency of tongue movements, reduction of face and chewing muscle function, increase in oral transit time, anterior escape of food, difficulty in formation, containment and ejection of food bolus, residues in oral cavity and early pharyngeal escape ${ }^{(3,15)}$. The pharyngeal phase also suffers changes, such as: lower frequency of spontaneous swallowing, less stability of laryngeal closure, slower pharyngeal contraction and pharyngeal stasis ${ }^{(3)}$.

The preparatory, oral and pharyngeal phases of swallowing were impaired by the different motor and sensory alterations of each disease. There was inefficiency in the preparation of the food bolus, loss of bolus control and increased oral transit. It should be pointed out that according to a previous study, the increase in oral transit time may be sensitive to detect about $75 \%$ of cases of laryngotracheal aspiration ${ }^{(16)}$.

The higher frequency of sensations with solid foods, observed in the present study, can be explained by the need for greater strength and range of motion, especially in the preparatory and oral phases. This consistency requires longer duration of transition stages between the phases of swallowing, as well as longer duration of velar excursion, longer duration of pharyngeal transit and duration of opening of the upper esophageal sphincter. More viscous foods may also lead to longer duration of pharyngeal contraction waves, increase in the number of multiple swallows to remove the bolus from the oral cavity and pharynx, increase in oral and pharyngeal transit time and increase in tongue strength required to initiate propulsion and transport of the bolus ${ }^{(3)}$.

Coughing during or after swallowing is a sign of airway permeation $^{(2)}$ and was noticed by practically all patients in whom laryngeal penetration or laryngotracheal aspiration was observed in the VFSS. Cough is a very common manifestation in the evaluation of dysphagia, since it is a response of the brainstem to protect the lower airway against the entrance of foreign bodies.

This sign can also be observed in patients with changes in the tongue musculature, since the inefficiency in this musculature may impair oral control and food ejection, increasing the risk of residual and premature escape of the food bolus, and may generate laryngeal penetration and / or laryngotracheal aspiration $^{(17)}$. In addition, pressure reduction during bolus ejection may increase the risk of non-closure of the inferior airway due to ineffective eversion of the epiglottis over the larynx atrium ${ }^{(3)}$.

Another clinical sign of penetration and/or aspiration associated with the number of perceived sensations was wet voice. Such a sign after swallowing may indicate the presence of secretions, liquids or food in the laryngeal vestibule, and may detect the silent permeation of the inferior airway ${ }^{(18)}$. In all the participants of the present study who reported perceiving change in voice after eating or drinking, lower airway permeation was observed by the instrumental evaluation of swallowing.

Although the average age of the participants did not indicate a predominantly elderly group, when considering the standard deviation and the maximum age observed, some individuals could, along with neurodegenerative diseases, have the aging process influence their swallowing. Aging alone may also lead to problems such as the need for longer duration of apnea during swallowing, greater probability of inspiration after swallowing and greater frequency of coughing after swallowing ${ }^{(3)}$, contributing to a dysphagic condition and corroborating with difficulty in breathing during the meal, referred by the older participants in this study.

It is noteworthy that the respiratory issue is a doubly important factor to be considered in the dysphagic patient. Primarily, it can affect swallowing due to instability in the oxygenation of the systems, which includes muscle function ${ }^{(5)}$ and secondarily can suffer from the complications of bronchoaspiration.

The combination between respiratory muscle weakness and low complacency of the lungs and chest wall causes an increase in respiratory rate, leading to the onset of fatigue of the breathing muscles ${ }^{(19)}$. This fact may contribute to the incoordination between the functions of breathing and swallowing and may also lead to the reduction of the apnea time necessary for the protection of the airways during swallowing.

A study of individuals with Parkinson's disease found that swallowing initiated after inspiration was related to longer duration of apnea during swallowing. Subjects who inspired after swallowing were observed to present greater occurrences of aspiration and penetration of liquid or food in the larynx ${ }^{(20)}$.

Although individuals with neurodegenerative diseases are known for the high incidence of pulmonary and nutritional complications due to dysphagia, only the most serious ones were under SLT follow-up. 
Patients treated in the early stages of disease are more likely to develop adaptive mechanisms to reduce the complications of dysphagia. There is a greater likelihood of compensating, replacing or using different neural substrates to produce a learning behavior or function adaptation ${ }^{(21,22)}$, even in patients with amyotrophic lateral sclerosis ${ }^{(23)}$.

A study conducted with individuals with Parkinson's disease showed improvement in swallowing and increased quality of life after five weeks of SLT intervention. The authors of the study believe that increasing patients' knowledge about swallowing promotes their ability to predict risk factors for aspiration, becoming aware of the importance of swallowing management ${ }^{(24)}$.

The non-performance of instrumental evaluation of swallowing in all participants is considered a limitation of this study. It is suggested that further studies be developed which include videofluoroscopic swallowing study in a larger population of individuals.

\section{CONCLUSION}

Most participants noticed changes in swallowing. Sensations such as burning, discomfort, annoyance, tiredness, pain, cramps or irritation when swallowing have been reported and have been associated with signs and symptoms that suggest a risk of laryngotracheal aspiration, especially due to muscle fatigue due to weakness, incoordination and/or muscle stiffness.

Unfortunately, it was observed that individuals started to manage swallowing late, which may have compromised compensatory mechanisms, evidenced in the literature as responsible for swallowing adaptations and consequent prevention of complications such as pneumonia, malnutrition, dehydration and even an increase in the expectation of life.

\section{REFERENCES}

1. Logemann JA. The evaluation and treatment of swallowing disorders. 2th ed. New York: Pro-ed; 1998.

2. Groher M, Crary M. Dysphagia: clinical management in adults and children. Mosby: Psc Editions; 2009.

3. Corbin-Lewis K, Liss JM, Sciortino KL. Anatomia clínica e fisiologia do mecanismo da deglutição. São Paulo: Cengage Learning; 2009.

4. Barker RA. Neurodegenerative disease processes. In: Daroff RB, Jankovic J, Mazziotta JC, Pomeroy SL. Neurology in clinical practice. 7th ed. New York: Elsevier, 2015. p. 1342-1348.

5. Oda AL, Oliveira ASB. Atendimento do paciente com doença neuromuscular na unidade de terapia intensidade. In: Furkim AM, Rodrigues KA. Disfagia nas Unidades de Terapia Intensiva. São Paulo: Roca; 2014. p. 173-188.

6. ADA: American Dietetic Association. National Dysphagia Diet: Standardization for Optimal Care. National Dysphagia Diet Task Force. Chicago: ADA; 2002.

7. Krupp LB, Larocca NG, Muir-Nash J, Steinberg AD. The fatigue severity scale. Application to patients with multiple sclerosis and systemic lupus erythematosus. Arch Neurol. 1989;46(10):1121-3. http://dx.doi.org/10.1001/ archneur.1989.00520460115022. PMid:2803071.

8. Hjollund NH, Andersen JH, Bech P. Assessment of fatigue in chronic disease: a bibliographic study of fatigue measurement scales. Health Qual
Life Outcomes. 2007;5(1):12. http://dx.doi.org/10.1186/1477-7525-5-12. PMid: 17326844 .

9. Valko PO, Bassetti CL, Bloch KE, Held U, Baumann CR. Validation of the fatigue severity scale in a Swiss cohort. Sleep. 2008;31(11):1601-7. http://dx.doi.org/10.1093/sleep/31.11.1601. PMid:19014080.

10. Neuberger GB. Measures of fatigue. The Fatigue Questionnaire, Fatigue Severity Scale, Multidimensional Assessment of Fatigue Scale, and Short Form-36 Vitality (Energy/Fatigue) Subscale of the Short Form Health Survey. Arch Neurol. 2003;49:175-83.

11. Ayres A, Ghisi M, Rieder CRM, Manor Y, Olchik MR. Tradução e adaptação cultural do Swallowing disturbance questionnaire para o português-brasileiro. Rev CEFAC. 2016;18(4):828-34. http://dx.doi. org/10.1590/1982-021620161844016.

12. Crary MA, Mann GDC, Groher ME. Initial psychometric assessment of a functional oral intake scale for dysphagia in stroke patients. Arch Phys Med Rehabil. 2005;86(8):1516-20. http://dx.doi.org/10.1016/j.apmr.2004.11.049. PMid:16084801.

13. Luchesi KF, Kitamura S, Mourão LF. Higher risk of complications in odynophagia associated dysphagia in amyotrophic lateral sclerosis. Arq Neuropsiquiatr. 2013;72(3):203-7. http://dx.doi.org/10.1590/0004282X20130244. PMid:24676437.

14. Thomas CK, Zijdewind I. Fatigue of muscles weakened by death of motoneurons. Muscle Nerve. 2006;33(1):21-41. http://dx.doi.org/10.1002/ mus.20400. PMid:16025525.

15. Orsoni M. Reabilitação nas doenças neuromusculares: abordagem interdisciplinar. São Paulo: Guanabara Koogan; 2012.

16. Kim Y, McCullough GH. Stage transition duration in patients poststroke. Dysphagia. 2007;22(4):299-305. http://dx.doi.org/10.1007/s00455-0079085-4. PMid:17610013.

17. Luchesi KF, Kitamua S, Mourão LF. Amyotrophic lateral sclerosis survival analysis: swallowing and non-oral feeding. NeuroRehabilitation. 2014;35(3):535-42. PMid:25238863.

18. Padovani AR, Moraes DP, Mangili LA, Andrade CRF. Protocolo Fonoaudiológico de Avaliação do Risco de Disfagia. Rev Soc Bras Fonoaudiol. 2007;12(3):199-205. http://dx.doi.org/10.1590/S1516-80342007000300007.

19. Ortiz KZ. Distúrbios neurológicos adquiridos: fala e deglutição. 2nd ed. Barueri: Manole; 2010.

20. Troche MS, Huebner I, Rosenbek JC, Okun MS, Sapienza CM. Respiratoryswallowing coordination and swallowing safety in patients with Parkinson's Disease. Dysphagia. 2010;26(3):218-24. http://dx.doi.org/10.1007/s00455010-9289-x. PMid:20623304.

21. Robbins J, Butler SG, Daniels SK, Diez Gross R, Langmore S, Lazarus $\mathrm{CL}$, et al. Swallowing and dysphagia rehabilitation: translating principles of neural plasticity into clinically oriented evidence. J Speech Lang Hear Res. 2008;51(1):276-300. http://dx.doi.org/10.1044/1092-4388(2008/021). PMid:18230851.

22. Suntrup S, Teismann I, Bejer J, Suttrup I, Winkels M, Mehler D, et al. Evidence for adaptive cortical changes in swallowing in Parkinson's disease. Brain. 2013;136(3):726-38. http://dx.doi.org/10.1093/brain/awt004 PMid:23412935.

23. Pontes RT, Orsini M, Freitas MRG, Antonioli RS, Nascimento OJM. Speech and swallowing disorders in amyotrophic lateral sclerosis: literature review. Rev Neurocienc. 2010;18(1):69-73.

24. Argolo N, Sampaio M, Pinho P, Melo A, Nóbrega AC. Do swallowing dynamic and quality of life in Parkinson's Disease? NeuroRehabilitation. 2013;32(4):949-55. PMid:23867420.

\section{Author contributions}

KFL contributed with study conception, analysis and interpretation of data, writing and review of the manuscript; BMC contributed with the collection and analysis of the data and writing of the manuscript; CTM contributed with the analysis, interpretation of data and manuscript revision. 